\title{
Servicios no personales y el empleo público
}

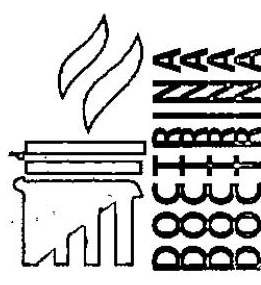

\section{Pedro G. Morales Corrales}

Abogado por la Universidad Nacional Mayor de San Marcos. Profesor de Derecho Individual del Trabajo en la Universidad de Lima.

Ex Presidente de la Sociedad Peruana de Derecho del Trabajo y de la Seguridad Social.

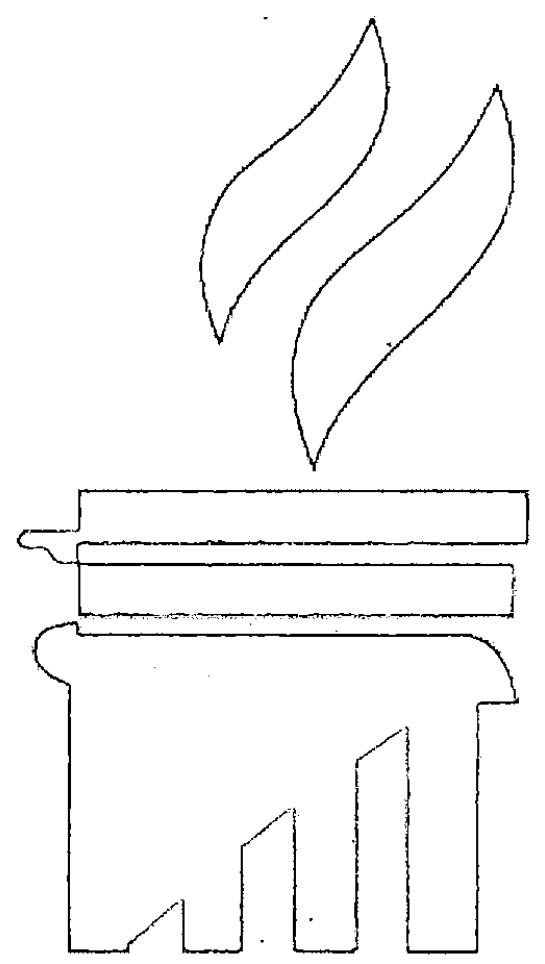

SUMARI0:

I. Introducción.

II. Antecedentes:

1. Régimen público;

2. Régimen privado;

3. Antecedentes remotos de los contratos de servicios no personales;

4. Inicio de la informalidad;

5. Antecedente más cercano;

6. Jurisprudencia.

III. El decreto legislativo y su reglamento:

1. Ámbito;

2. Naturaleza juridica y definición del contrato administrativo de servicios;

3. Procedimiento de contratación;

4. Impedimentos para contratar y prohibición de doble percepción;

5. Duración;

6. Contenido del contrato - Derechos y beneficios;

7. Ius variandi;

8. Suspensión del contrato;

9. Extinción del contrato;

10. Solución de controversias;

11. Responsabilidad administrativa y civil.

IV. Comentarios finales. 


\section{INTRODUCCIÓN}

El 28 de junio de 2008 se publicó en el Diario Oficial El Peruano el Decreto Legislativo 1057, en adelante "el Decreto Legislativo" que regula el "Régimen Especial de Contratación Administrativa de Servicios", persiguiendo como objeto central garantizar los principios de méritos y capacidad, igualdad de oportunidades y profesionalismo de la administración pública (artículo 1) de aquellos servidores que venían siendo contratados como "servicios no personales".

Esta conclusión se infiere de la Primera, Segunda y Cuarta Disposiciones Complementarias del indicado dispositivo, que establecen: (i) que las referencias normativas a la contratación de servicios no personales se entienden realizadas a la contratación administrativa de servicios; (ii) que las prohibiciones de contratación de servicios no personales reguladas en las normas de presupuesto son aplicables a la contratación administrativa de servicios; $y$, (iii) que las entidades comprendidas en el Decreto Legislativo (es decir las sujetas al Decreto Legislativo 276 - Ley de Bases de la Carrera Administrativa y de Remuneraciones del Sector Público- y a otras normas que regulan carreras administrativas especiales, así como las entidades públicas sujetas al régimen laboral de la actividad privada, con excepción de las empresas del Estado) quedan prohibidas en lo sucesivo de suscribir o prorrogar contratos de servicios no personales o de cualquier modalidad contractual para la prestación de servicios no autónomos, facultando a las partes a sustituir dichos contratos antes de su vencimiento con contratos celebrados bajo el régimen especial de contratación administrativa de servicios.

De acuerdo a su Exposición de Motivos, el Decreto Legislativo tiene por objeto constituir "(...) una fórmula normativa transitoria que equilibre las protecciones e inicie un proceso de reordena-
Público y sus normas de desarrollo", aún cuando el indicado propósito no ha sido expresamente consignado en el Decreto Legislativo.

Lo cierto es que el Decreto Legislativo trata de remediar aunque parcialmente, la situación de iniquidad en que se encontraban cerca de ochenta mil' servidores públicos que, con violación de las normas vigentes sobre su incorporación a la Ley de la Carrera Administrativa o dentro del marco de régimen laboral de la actividad privada, en aquellos organismos públicos en que por ley expresa sus servidores se encontraban comprendidos en dicho régimen, fueron contratados bajo el sistema de "servicios no personales", que como veremos más adelante resultaba un neologismo de lo que se conoce jurídicamente como contrato de "locación de servicios" que se encuentra regulado por el Código Civil y que supone, en esencia, que su prestación se realiza de manera independiente $o$ autónoma, cuando en la realidad de los hechos, estos miles de servidores públicos laboraban de manera permanente y ejecutando labores propias de la función pública pero desconociéndoseles todos sus derechos y beneficios y el acceso a la seguridad social.

Con fecha 25 de noviembre de 2008 se ha publicado en el Diario Oficial El Peruano el Reglamento de este Decreto Legislativo, aprobado mediante Decreto Supremo No. 075-2008-PCM, en adelante "el Reglamento".

Para poder entender los avances y limitaciones que suponen la vigencia del Decreto Legislativo y su Reglamento, así como las contingencias que a nuestro juicio aún persisten, resulta de interés conocer con más detalle cómo es que se llegó a esta situación límite que ha obligado al Estado, aunque tímidamente, a iniciar el camino de la formalización, que nunca debió obviar en la contratación de un importante sector de servidores públicos. Lo sustantivo es que se ha iniciado la rectificación del Estado-Empleador de la mala

1 Según información del Ministerio de Economía y Finanzas con motivo de la formulación de esta norma, el número exacto de contratados bajo el sistema de servicios no personales era de 77,787 servidores públicos. 
práctica en que venía incurriendo, violando derechos de sus trabajadores y perdiendo calidad moral para exigir al sector privado el cumplimiento de sus obligaciones laborales.

\section{ANTECEDENTES}

\section{Régimen público}

La Constitución vigente en su artículo 39 establece que "Todos los funcionarios y trabajadores públicos están al servicio de la Nación (...)".

A su vez, el artículo 40 de la Carta establece que "La ley regula el ingreso a la Carrera Administrativa, los derechos, deberes y responsabilidades de los servidores públicos. No están comprendidos en dicha carrera los funcionarios que ejerzan cargos políticos o de confianza. Igualmente no están comprendidos en la función pública, los trabajadores de las empresas del Estado o de sociedades de economíamixta".

El Decreto Ley 11377 -Estatuto y Escalafón del Servicio Civil- norma que dio origen al tratamiento ordenado del régimen laboral público, definió en su artículo 1 a los empleados públicos en la siguiente forma:

\section{"Artículo 1.- Considérase empleado público a toda persona que desempeñe labores remu- neradas en las Reparticiones del Estado. \\ Los que realicen labores propias de obre- ros en las dependencias públicas, estarán comprendidos solo en las disposiciones que especificamente se han dictado para estos servidores a excepción del servicio interno que se acogerán a las disposiciones del pre- sente Estatuto".}

El Reglamento del Decreto Legislativo 276, aprobado por Decreto Supremo No. 005-90PCM, de 17 de enero de 1990, en su artículo 3 entiende por servidor público "(...) al ciudadano en ejercicio que presta servicio en entidades de la Administración Pública con nombramiento o contrato de autoridad competente, con las formalidades de ley, en jornada legal y sujeto a retribución remunerativa permanente en periodos regulares".
A su vez el artículo 2 del Decreto Ley 11377 define lo que debe entenderse por "Repartición del Estado" en los siguientes términos:

a) "Artículo 2.- Para los efectos de esta Ley, se denominará genéricamente "repartición":

En el Poder Ejecutivo, a cada Ministerio, sin perjuicio de las excepciones que establezca el Reglamento.

b) Las Municipalidades

c) Las entidades fiscales y fiscalizadas y todas aquellas que realicen alguna función estatal.

d) En las Sociedades de Beneficencia Pública a cada ramo con autonomía administrativa".

El Decreto Legislativo 276, de 6 de marzo de 1984, que aprobó la Ley de Bases de la Carrera Administrativa y de Remuneraciones del Sector Público, en su artículo 1 define la Carrera Administrativa como "(...) el conjunto de principios, normas y procesos que regulan el ingreso, los derechos y los deberes que corresponden a los servidores públicos, que, con carácter estable prestan servicios de naturaleza permanente en la administración pública", no encontrándose comprendidos en la Carrera Administrativa los servidores públicos contratados, ni los funcionarios que desempeñan cargos políticos o de confianza, pero sí en las disposiciones de la indicada ley en lo que les sea aplicable (artículo 2). El ingreso procede siempre que el postulante haya sido aprobado en el concurso de admisión respectivo (artículo $12 \mathrm{~d}$ ). Este aspecto es muy importante, como lo veremos más adelante, pues colisiona con algunas sentencias que ordenan la regularización de la situación del servidor despedido y repuesto.

El mismo artículo 2 excluye de la Carrera Administrativa y de los alcances del Decreto Legislativo 276 a los miembros de Fuerzas Armadas y Fuerzas Policiales y a los trabajadores de las empresas del Estado o de sociedades de economía mixta, cualquiera sea su forma jurídica.

A su vez, el artículo 15 del Decreto Legislativo 276 , establece que la contratación de un servidor para realizar labores administrativas de naturaleza permanente, no puede renovarse por 
más de tres años consecutivos. Vencido este plazo el servidor que haya venido desempeñando tales labores, podrá ingresar a la Carrera Administrativa previa evaluación favorable y siempre que exista plaza vacante, reconociéndosele el tiempo de servicios prestados como contratado para todos sus efectos. Este mismo dispositivo precisa que no es aplicable a los servicios que por su propia naturaleza sean accidentales o temporales.

El artículo 39 del Reglamento, en concordancia con el artículo 15 del Decreto Legislativo 276 antes glosado determina que la contratación de un servidor para labores de naturaleza permanente será excepcional y que solo procederá en caso "de máxima necesidad y debidamente fundamentada por la autoridad competente".

El Reglamento del Decreto Legislativo 276, en su artículo 38 señala que las entidades de la administración pública solo podrán contratar personal para realizar funciones de carácter temporal o accidental para: (i) obra o actividad determinada; (ii) labores en proyectos de inversión y proyección especiales, cualquiera sea su duración; y, (iii) labores de reemplazo de personal permanente impedido de prestar servicios, siempre y cuando sea de duración determinada.

Hasta acá puede apreciarse que la norma general es que un servidor público que realiza una labor de naturaleza permanente debe entrar a la Carrera Administrativa y que solo excepcionalmente puede ser contratado a plazo cuando exista una "máxima necesidad debidamente fundamentada por la autoridad competente".

Además, hay que tener en cuenta que conforme al artículo 1 de la Ley 24041, de 27 de diciembre de 1984 (anterior al Reglamento del Decreto Legislativo 276), los servidores públicos contratados para labores de naturaleza permanente, que tengan más de un año ininterrumpido de servicios, no pueden ser cesados ni destituidos sino por las causas previstas en el Capítulo $\mathrm{V}$ del Decreto Legislativo 276 y con sujeción al procedimiento establecido en él, sin perjuicio de lo dispuesto en el artículo 15 de la misma ley, lo que en otras palabras significa que una vez superado un año ininterrumpido de servicios, así se prorrogue el contrato hasta el máximo de tres años previsto en dicho artículo, el servidor legalmente no puede ser cesado por conclusión del mismo porque gozaría de la estabilidad laboral absoluta regulada por el indicado Decreto Legislativo. En realidad, la Ley 24041 estaría otorgando a estos trabajadores contratados el beneficio de la estabilidad laboral absoluta al año de servicios y el derecho de incorporarlos a la Carrera Administrativa a los tres años de contratado, siempre que exista plaza vacante.

El artículo 2 de esta norma excluye del beneficio establecido en su artículo 1 glosado a los servidores públicos contratados para desempeñar labores de naturaleza accidental o temporal, tales como (i) trabajo para obra determinada; (ii) labores en proyectos de inversión, proyectos especiales, en programas de actividades técnicas, administrativas y ocupacionales, siempre y cuando sean de duración determinada; (iii) labores eventuales o accidentales de corta duración; y (iv) funciones políticas o de confianza.

Los servidores comprendidos en la Carrera Administrativa tienen, en síntesis, los siguientes derechos $y$ beneficios:

a) Jornada de trabajo: Conforme al Decreto Legislativo 800, la jornada de trabajo de los servidores públicos es de siete horas con cuarenta y cinco minutos en horario corrido.

b) Trabajo en sobretiempo: Este debe ser remunerado en forma proporcional al haber básico del servidor, prohibiéndose su pago a los funcionarios (Ley, artículo 55).

Desde hace muchos años las normas de austeridad presupuestal prohiben el pago de horas extras.

c) Estabilidad laboral: según el cual ningún servidor puede ser cesado ni destituido sino por causa prevista en la ley y previo procedimiento administrativo (Ley, artículo 24, inciso b y Reglamento, artículo 100). 
d) Vacaciones: de treinta días al año, salvo acumulación convencional de hasta dos periodos (Ley, artículo 24 inciso d y Reglamento, artículo 102).

e) Permisos: Pueden ser: (i) por razones excepcionales debidamente fundamentadas para ausentarse por horas del centro laboral durante la jornada de trabajo, sin que excedan de un día por mes; y (ii) para ejercer la docencia universitaria hasta por un máximo de seis horas a la semana, que debe ser compensado. Similar derecho se concederá a los servidores que sigan estudios superiores con éxito (Ley, artículo 24, inciso e y Reglamento, artículos 106 y 107).

f) Licencias con goce de remuneración: Se otorgan por.(i) enfermedad; (ii) gravidez; (iii) fallecimiento del cónyuge, padres, hijos o hermanos; (iv) capacitación oficializada; y (v) citación judicial, militar o policial (Ley, artículo 24, inciso e y Reglamento, artículos 109 y 110).

La licencia por enfermedad y gravidez, se otorga conforme a las disposiciones de ESSALUD. La licencia por fallecimiento en los casos antes mencionados, se otorga por cinco días en cada caso, pudiendo extenderse hasta tres días más, cuando el deceso se produce en lugar geográfico diferente en donde labora el servidor. La licencia por capacitación oficializada, en el país o en el extranjero, se otorga hasta por dos años al servidor de carrera, siempre que se cumplan determinadas condiciones: (i) contar con el auspicio o propuesta de la entidad; (ii) estar referida al campo de acción institucional y especialidad del servidor; $y$, (iii) compromiso de servir a su entidad por el doble del tiempo de licencia, contado a partir de la reincorporación (Reglamento, artículos 111, 112 y 113).

La licencia por citación expresa de la autoridad judicial, militar o policial competente, se otorga al funcionario o servidor que acredite la notificación con el documento oficial respectivo. Abarca el tiempo de la concurrencia más los términos de la distancia (Reglamento, artículo 114).

g) Licencia sin goce de remuneraciones: que pueden ser por: (i) motivos particulares; (ii) capacitación no oficializada a cuenta del periodo vacacional; $y$ (iii) por matrimonio o por enfermedad grave del cónyuge, padres o hijos (Ley, artículo 24 inciso e) y Reglamento, artículos 109 y 110).

La licencia por motivos particulares podrá otorgarse hasta por noventa dias en un periodo no mayor de un año de acuerdo con las razones que exponga el servidor $y$ las necesidades del servicio (Reglamento, artículo 115).

La licencia por capacitación no oficializada se otorga hasta por doce meses, obedece al interés personal del servidor y no cuenta con el auspicio institucional (Reglamento, artículo 116).

Las licencias sin goce de remuneración no son computables como tiempo de servicios en la administración pública para ningún efecto (Reglamento, artículo 117, ejemplo: Bonificación por quinquenio, compensación por tiempo de servicios).

Las licencias por matrimonio y por enfermedad serán deducidas del periodo vacacional inmediato siguiente del funcionario o servidor, sin exceder de treinta días (Reglamento, artículo 118).

h) Hora de lactancia: Al término del periodo post natal, la madre trabajadora tiene derecho a una hora diaria de permiso por lactancia hasta que su hijo cumpla un año de edad (Reglamento, artículo 108).

i) Bonificaciones: Existen tres tipos de bonificaciones: (i) La personal; que corresponde a la antigüiedad en el servicio, computada por quinquenios a razón de $5 \%$ del haber básico o el que lo sustituya, sin exceder de ocho quinquenios; (ii) la bonificación familiar, que corresponde a las cargas familiares. Si 
la madre y el padre son servidores públicos, esta bonificación se paga a la madre; $y$, (iii) la bonificación diferencial que compensa los cargos de responsabilidad directiva y las condiciones de trabajo excepcionales respecto del servicio común. Esta bonificación no es aplicable a los funcionarios (Ley, artículos 43, 51 y 52 ).

j) Asignación por cumplir 25 o 30 años de servicios: Se otorga por un monto equivalente a dos remuneraciones mensuales totales al cumplir veinticinco (25) años de servicios y tres remuneraciones mensuales al cumplir treinta (30) años de servicios. Se concede por única vez en cada caso (Ley, artículo 54-A).

k) Aguinaldos: Se otorgan en Fiestas Patrias y Navidad, por el monto que se fije por Decreto Supremo cada año (Ley, artículo 54 inciso b).

I) Compensación por tiempo de servicios: Se otorga al personal nombrado en la oportunidad del cese y es igual al $50 \%$ de la remuneración principal, se entiende por cada año de servicios, y siempre que se trate de trabajadores con menos de 20 años de servicios, y del $100 \%$ o una remuneración principal para aquellos que cesan con 20 o más años de servicios y hasta por un máximo de 30 años de servicios. En caso de récord trunco se considera año completo a la fracción mayor de seis meses. El pago de este beneficio tiene efecto cancelatorio (Ley, artículo 54 inciso c), tal como ha quedado modificada por la Ley 25224.

m) Derechos colectivos: Los servidores públicos tienen derecho a la sindicalización y huelga, no así a la negociación colectiva de condiciones de trabajo o beneficios que impliquen incremento de remuneraciones. No están comprendidos los funcionarios del Estado con poder de decisión y los que desempeñan cargos de confianza o de dirección, así como los miembros de las Fuerzas Armadas o de la Policía Nacional. Las entidades públicas al otorgar derechos y beneficios, no pueden discriminar entre servidores sindicalizados y no sindicalizados. Las organizaciones sindicales representan a sus afiliados en los asuntos que establece la norma respectiva, sus dirigentes gozan de facilidades para ejercer la representatividad legal (Constitución, artículo 42; Ley, artículo 24 incisos (I) y $\mathrm{m}$ ) y 44; Reglamento, artículos 120, 121 y 122).

n) Otros Derechos: (i) hacer carrera pública en base al mérito, sin discriminación de ninguna clase; (ii) obtener préstamos administrativos, de acuerdo a las normas pertinentes; (iii) reincorporarse a la carrera pública al término del desempeño de cargos electivos, en los casos que la ley indique; (iv) recibir menciones, distinciones y condecoraciones de acuerdo a los méritos personales; $(v)$ reclamar ante las instancias y organismos correspondientes de las decisiones que afecten sus derechos; (vi) acumular a su tiempo de servicios hasta cuatro años de estudios universitarios (título reconocido por la Ley Universitaria), después de quince años de servicios efectivos, siempre que no sean simultáneos; (vii) no ser trasladado a entidad distinta sin su consentimiento; (viii) gozar al término de la carrera de pensión, dentro del régimen que le corresponda; (ix) los demás que señalen la Ley o el Reglamento (Ley, artículo 24, incisos a), f), g), i), j), k), l), n), ñ) y Reglamento, artículos 96 y 105).

Los derechos reconocidos por el Decreto Legislativo 276 a los servidores públicos son irrenunciables. Toda estipulación en contrario es nula (Ley, artículo 24, párrafo final).

\section{Régimen privado}

Sin embargo, y de acuerdo a lo expresado en el Resumen Ejecutivo formulado por la Comisión Multisectorial encargada de estudiar la situación del personal de la administración pública central, creada mediante Decreto Supremo No. 0042001-TR, "a mediados de la década de los noventa dentro de un proceso de reforma del Estado que quedó trunco, una serie de entidades e instituciones públicas comenzó a migrar hacia el régimen laboral privado: entre ellas algunas totalmente nuevas-como INDECOPI, OSINERG (actualmente 
OSINERGMIN), CONASEV-, otras reconstituidas - como la Contraloría General de la República, SUNATY Aduanas-; e incluso algunas instituciones paradigmáticamente públicas y estatales como el Poder Legislativo y el Poder Judicial".

Antes, aunque fueron reducidos los casos, ya existían entidades públicas cuyos servidores se encontraban regulados por el régimen laboral de la actividad privada, como el Banco Central de Reserva y la Superintendencia de Banca y Seguros. Así lo reconoce el propio Decreto Legislativo 276 en su Quinta Disposición Final.

Hoy, podría decirse, que más son lọs organismos públicos en general cuyos servidores han sido incorporados por ley expresa ${ }^{2}$ al régimen laboral de la actividad privada, que aquellos que continúan comprendidos en la Carrera Administrativa.

Cabe señalar que la indicada migración se debió fundamentalmente a la flexibilidad de las normas que regularon en la década del noventa la actividad laboral en el régimen privado, fundamentalmente en lo que se refería a la estabilidad laboral, cuya norma general consistía en que frente a un despido injustificado la única reparación era el pago de una indemnización en tanto que la norma de excepción era la reposición en los supuestos de despidos nulos; mientras que como ya lo hemos dicho los servidores comprendidos en la Carrera Administrativa gozan de estabilidad laboral absoluta (radical), en el sentido de que no pueden ser despedidos sin que previamente en sede administrativa se haya acreditado la causal de falta grave.

Tal razón (flexibilidad en el despido) a nuestro juicio era exactamente el motivo que jamás debió tenerse en cuenta para la incorporación de miles de servidores públicos al régimen laboral de la actividad privada. El motivo que debió primar en todo caso debió ser la paulatina incor- poración a un régimen laboral único, el privado, por ser más beneficioso, debiendo consolidarse en el futuro en un solo régimen laboral, omitiéndose la calificación de "privado" y en todo caso contemplando capítulos especiales para dar un tratamiento singular a aquellos aspectos propios que surgen como consecuencia de la calidad del empleador, en este caso del Estado. Los servidores públicos, por ser el Estado su empleador, y por el rol de columna vertebral de la actividad estatal que desempeñan, deben gozar de estabilidad laboral absoluta a fin de preservar dicho rol y de evitar los abusos que puedan cometerse contra dichos servidores, despidiéndolos por razones de clientelaje politico, y pagando indemnizaciones con dinero de los contribuyentes.

Si la razón de pasarlos al régimen laboral de la actividad privada fue el tratamiento flexible en materia de estabilidad laboral, que además es lo que ocurre en la mayor parte de los países del mundo, tal razón desapareció con el criterio vinculante establecido por el Tribunal Constitucional en su ya famosa Resolución, de 13 de mayo de 2003, recaída en el Expediente No. 9762001-AA/TC caso Eusebio Llanos Huasco contra Telefónica del Perú S.A., criterio desde nuestro punto de vista errado, que nos ha regresado a la estabilidad laboral absoluta de mediados de la década del 80 .

Lo cierto es que a la fecha coexisten estos dos regímenes, sin mencionar los especiales.

\section{Antecedentes remotos de los contratos de servicios no personales}

Hemos encontrado como antecedente más remoto de los contratos de servicios no personales, a la Directiva No. 02-83-EFC/76.01, aprobada por Resolución Directoral No. 116-83-EFC/76.01, de 22 de diciembre de 1983, Anexo No. 4 denominado "Clasificador por Objeto del Gasto",

2 El régimen natural de los servidores públicos es el de la Carrera Administrativa conforme al Decreto Legislativo 276, por lo que solo por ley (mismo rango normativo) se les puede excluir de dicho régimen natural e incorporar al régimen laboral de la actividad privada. 
que distingue entre los servicios personales y servicios no personales, entendiéndose por los primeros los que son prestados directamente por personas naturales en relación de dependencia, mientras que los servicios no personales, son aquellos prestados por personas naturales, sin relación laboral directa y por personas juridicas.

Boris Potozén ${ }^{3}$ encuentra como una referencia remota al antiguo "Reglamento Único de Adquisiciones Para el Suministro de Bienes y Prestación de Servicios no Personales - RUA", aprobado por Decreto Supremo No. 065-85PCM (19/07/1985), que según el autor, "en su propia denominación, la norma acuñó la terminología-Servicios No Personales-la que ha tenido vigencia hasta estos últimos dias, incluso más allá de haber quedado sin efecto por la entrada en vigor de la Ley 26850, Ley de Contratación y Adquisiciones del Estado".

Explica el citado autor que "el RUA como disposición de carácter administrativo, constituyó un cuerpo normativo orgánico que estandarizó los diversos procedimientos o reglamentos de adquisiciones que de manera desordenada y dispersa existían en el Estado, teniendo el propósito de constituirse en la norma que regularía los procesos de adquisiciones de bienes y la prestación de servicios autónomos (compra de bienes, suministros, alquileres, locación de servicios, etc.) incluyendo su contratación. Asi, cuando el Estado requeria de la provisión de servicios, satisfacía sus necesidades recurriendo a la modalidad de contratos de servicios no personales" (el subrayado es nuestro). Esta norma definió a los "servicios no personales" como la "actividad o trabajo que efectúa una persona natural o jurídica ajena al organismo público que desea adquirir, a cambio de una retribución económica, para atender una necesidad intangible. Se orienta a la producción, construcción, habilitación, funcionamiento, orientación, conservación, preservación uotros; se mide en y por sus efectos o resultados" (el subrayado es nuestro).

Queda claro entonces que los antecedentes más remotos de esta prestación de"servicios no personales", estaban indudablemente vinculados a lo que en el Código Civil se conoce como "contratos de locación de servicios", porque tanto en el primero como en este último, como ya lo hemos expresado, los servicios se prestan de manera independiente, es decir sin que medie vinculación de subordinación, porque de suceder esto último, nos encontraríamos frente a una prestación personal de servicios, es decir un contrato de trabajo con todas sus consecuencias.

En efecto, en normas más recientes, como por ejemplo la Directiva No. 012-2006-EF/76.01, aprobada por Resolución Directoral No. 0292006-EF/76.01, de 2 de junio de 2006, contiene un Glosario de Definiciones, y refiriéndose a los "servicios no personales" (SNPs) señala que se trata de "personas naturales que han firmado un contrato de locación de servicios con las Unidades Ejecutoras".

De acuerdo a tales antecedentes, de haberse aplicado correctamente no tendrian por qué haber generado ningún problema, porque en efecto, tratándose de servicios realmente autónomos o independientes estos no generaban más obligaciones que el pago del honorario pactado y la retención del impuesto a la Renta correspondiente. Nada más.

\section{Inicio de la informalidad}

Lo cierto es que frente a las normas de austeridad contenidas en las leyes de Presupuesto, que prohibían la contratación de personal, por lo cual la incorporación dentro de la Carrera Administrativa durante muchos años fue prácticamente inexistente, siendo tampoco posible

3 POTOZÉN BRACO, Boris Gonzalo, El Régimen Especial de Contratación Administrativa de Servicios, A Propósito de la reciente publicación del Decreto Legislativo 1057. En: Revista Jurídica del Perú, No. 90, Agosto, 2008, p. 165. 
la contratación de servidores públicos permanentes bajo el régimen laboral de la actividad privada, muchos titulares de pliegos frente a la real necesidad de contar con trabajadores para satisfacer las funciones públicas a su cargo, no encontraron mejor forma que utilizar los contratos por servicios "no personales" para así aparentar que cumplian con las normas de austeridad, cuando en la realidad de los hechos lo que estaban haciendo era contratar a personal subordinado pero aplicándose las normas de la locación de servicios que los excluyen de cualquier derecho o beneficio social y de seguridad social, es decir el Estado con esta práctica comenzó a informalizarse y a precarizar el trabajo de miles de servidores públicos.

\section{Antecedente más cercano}

El antecedente más cercano e importante que ha influido en la dación del Decreto Legislativo 1057, es sin duda el Informe Final presentado por la Comisión Multisectorial encargada de estudiar la situación del personal de la Administración Pública Central de 15 de julio de 2001, al que nos hemos referido anteriormente, que da cuenta del desorden prácticamente absoluto en el tratamiento de los servicios y remuneraciones de los servidores públicos que hacían imprescindible una reforma profunda en este ámbito del Estado.

Refiriéndose a los contratos de servicios no personales manifiesta este Informe que "no corresponde a ninguna categoría jurídica o específica, al no tener precedentes normativos ni doctrinarios y tampoco una adecuada precisión legal, pues hasta ahora, salvo menciones aisladas en normas dispersas, como por ejemplo la Ley de Contrataciones y Adquisiciones del Estado, no se han precisado sus alcances a través de ninguna norma especifica. Esta falta de regulación adecuada genera un vacio legal que podría dar lugar a interpretaciones que, extrapolando conceptos del derecho administrativo y del derecho laboral, apliquen a estos contratos principios o criterios inadecuados y hasta incompatibles con su naturaleza. Como resultado de ello, la Comisión ha elaborado un proyecto de norma regulatoria a través de la cual se sustituye dicha modalidad extraña de contratación por un nuevo contrato denominado "contrato administrativo de servicios", cuya principal virtud es reconocer a dichos trabajadores los derechos consagrados por la Constitución y por los Convenios Internacionales ratificados por el Perú, que son norma interna de la República. Asimismo se consagra que dichos trabajadores deben ser asegurados obligatorios de Essalud e inscribirse en alguno de los sistemas pensionarios existentes. Ahora bien, como la Constitución señala que no se puede, a través de una ley, modificar el contenido de un contrato $-y$ este Gobierno es y será respetuoso de la Constitución-, esta propuesta normativa señala que para variar los contratos vigentes y acogerse al nuevo sistema, más favorable al trabajador, debe haber acuerdo de partes. Caso contrario, se aplicará el contrato vigente hasta el final del plazo estipulado, pero ya no podrá ser renovado o prorrogado a su vencimiento".

Consideramos que el Informe, tal vez por razones de pudor político soslayó una realidad: No se trata, como se sostiene, que el contrato de servicios no personales "no corresponde a ninguna categoría jurídica o específica, al no tener precedentes normativos ni doctrinarios (...)", por cuànto, como se ha visto de los antecedentes, dicha modalidad contractual estaba expresamente prevista pero para servicios autónomos, jamás para servicios personales y por ende subordinados. Lo cierto es que en los hechos se mal utilizó dicho contrato para evadir las normas de austeridad consagradas en el Presupuesto iniciando el Estado un camino de informalización al cual jamás debió recurrir.

\section{Jurisprudencia}

Tan cierto es lo expresado que la reiterada jurisprudencia de la Corte Suprema de la República y Tribunal Constitucional, así lo demuestran. Podríamos mencionar docenas de resoluciones en las que se plantearon procesos de amparo de servidores contratados bajo dicha modalidad quienes, al no renovárseles los contratos recurrieron a esa vía y obtuvieron su reposición, aplicándose para ello el principio de primacía de la realidad, según el cual prevalece lo que ocurre en los hechos y no lo que figura en los documen- 
tos, en este caso en los contratos de "locación de servicios" o "servicios no personales".

Nos exoneramos de citar dicha jurisprudencia habida cuenta que existe un artículo que la analiza de manera muy puntual, titulado "Consideraciones en torno a la Jurisprudencia Constitucional sobre los Contratos de Servicios No Personales", cuyo autor es el laboralista Carlos Guillermo Morales Morante, publicado en el libro "Estudio sobre la Jurisprudencia Constitucional en Materia Laboral y Previsional" de la Academia de la Magistratura y la Sociedad Peruana de Derecho del Trabajo y de la Seguridad Social (Segraf-Editora Perú S.A., Octubre de 2004, p. 237).

\section{EL DECRETO LEGISLATIVO Y SU REGLAMENTO}

Como hemos señalado en la Introducción, el Decreto Legislativo y su Reglamento regulan el "Régimen Especial de Contratación Administrativa de Servicios" y comprende en esas normas a los servidores que a la fecha de su vigencia se encontraban contratados bajo el sistema de "servicios no personales", pero también regula hacia el futuro esta forma de contratación cuando asi lo autorice o, mejor dicho, no lo prohíban las normas de austeridad presupuestales.

\section{1. Ámbito (Decreto Legislativo artículo 2, Reglamento artículo 2)}

Este régimen especial es aplicable a toda entidad pública sujeta al Decreto Legislativo 276 y otras normas que regulan carreras administrativas especiales. Boris Potozén cita como ejemplo de este tipo de carreras "a los trabajadores de las Fuerzas Armadas, trabajadores de las Fuerzas Policiales, trabajadores médicos, trabajadores(as) enfermeros(as), trabajadores cirujanos dentistas, trabajadora obstetriz, trabajadores profesores, trabajadores psicólogos, trabajadores químico farmacéuticos, trabajadores técnicos y auxiliares asistenciales, de salud, trabajadores tecnólogos médicos, trabajadores diplomáticos, etc." ${ }^{4}$

4 POTOZÉN BRACO, Boris Gonzalo, Op. Cit., p.158.
Asimismo comprende a las entidades públicas sujetas al régimen laboral de la actividad privada con excepción de los trabajadores de las empresas del Estado que, como se ha mencionado anteriormente, se encuentran excluidas constitucionalmente de la función pública.

El Reglamento entiende como entidades de la administración pública, al Poder Ejecutivo, incluyendo los ministerios y organismos públicos (OPD), de acuerdo a lo establecido por la Ley Orgánica del Poder Ejecutivo; al Congreso de la República, al Poder Judicial; a los organismos constitucionalmente autónomos, a los gobiernos regionales y locales, a las universidades públicas, y a las demás entidades públicas cuyas actividades se consideran sujetas a las normas comunes de derecho público.

Sin embargo, excluye del ámbito los siguientes supuestos de contratación: (i) los contratos financiados directamente por alguna entidad de cooperación internacional, con cargo a sus propios recursos, lo que es entendible; (ii) los contratos que se realizan a través de organismos internacionales que, mediante convenio, administran recursos del Estado Peruano para fines de contratación de personal altamente calificado lo que a nuestro juicio no es correcto como se explicará más adelante; (iii) los contratos del Fondo de Apoyo Gerencial a que se refiere el Decreto Legislativo 1024 que contempla un tratamiento especial en cuanto a derechos y beneficios justificables por el nivel de estos servidores públicos; (iv) los convenios sobre modalidades formativas laborales, toda vez que no crea vínculo laboral; y, (v) los contratos de prestación y locación de servicios, consultoría, asesoria o cualquier otra modalidad contractual de prestación de servicios autónomos o independientes que se realizan fuera del local de la entidad contratante.

Respecto del supuesto (ii), que no es otro que los contratos en que interviene la PNUD, en el fondo se persevera en la simulación o fraude, 
por cuanto estos servidores públicos son contratados a través de dicho organismo otorgándose los derechos exclusivamente contenidos en los respectivos contratos que en el fondo son similares, sino idénticos a los de locación de servicios, propios de la prestación de servicios independiente o autónoma, es decir: ninguno. La norma reserva este tipo de contratación para "personal altamente calificado", lo que no siempre ocurre poniendo en evidencia además, que se trata de un subterfugio para pagar retribuciones de acuerdo al mercado y no las limitaciones antitécnicas vigentes que establecen topes remuneratorios de acuerdo a la categoría, que son irreales y que lo único que originan es la pérdida de funcionarios calificados y su sustitución por servidores mediocres.

Resulta imprescindible que se regule de manera transparente la contratación y las remuneraciones de los servidores públicos, de tal modo de asegurar que el Estado cuente con un equipo tan y mejor calificado que aquel que presta servicios en el sector privado, pues no hay empresa más importante que el Estado que tiene como misión atender las necesidades fundamentales del país a través de su aparato estatal.

\section{Naturaleza jurídica y definición del contrato administrativo de servicios (Reglamento, artículo 1)}

El Decreto Legislativo lo define como "una modalidad especial propia del derecho administrativo y privativo del Estado". El Reglamento lo desarrolla de la siguiente manera: El Contrato Administrativo de Servicios es una modalidad contractual administrativa y privativa del Estado, que vincula a una entidad pública con una persona natural, que presta servicios de manera no autónoma. Se rige por normas de Derecho público y confiere a las partes únicamente los beneficios y las obligaciones que establece el Decreto Legislativo y el Reglamento; no encontrándose sujeto a las disposiciones del Decreto Legislativo 276 -Ley de Bases de la Carrera Administrativa y de Remuneraciones del Sector Público-, ni al régimen laboral de la actividad privada ni a ningún otro régimen de carrera especial.
Esta norma intenta crear un régimen especial de contratación para este tipo de servidores públicos "no autónomos", es decir dependientes del Estado, tratando de diferenciarlos del régimen laboral público (carrera administrativa) o del régimen laboral privado aplicable a aquellos servidores públicos que pertenecen a entidades del Estado que por mandato expreso de la ley han sido incorporados a dicho régimen laboral.

Consideramos que ello no es posible por cuanto no se trata de un régimen o contrato especial, pues carece de elementos distintivos que podrían ser los supuestos que hemos enumerado anteriormente de carreras administrativas especiales; más aún por el origen de este tipo de contratación que, como ya se ha expresado, es ilícito, pues procede de una simulación o fraude pues a estos servidores se les contrató como "servicios no personales", es decir como trabajadores independientes o autónomos cuando en la realidad de los hechos eran dependientes. De ahi que la solución jurídica y jurisprudencial es que dichos servidores deben incorporarse al régimen que a cualquiera de los dos regímenes antes mencionados, dependiendo de la norma que se aplique en la respectiva entidad pública. Claro es que no es fácil la incorporación al régimen de la Carrera Administrativa porque requiere del cumplimiento de una serie de condiciones o requisitos entre ellos que exista plaza vacante y que se ingrese por concurso, lo que constituye un óbice para los trabajadores SNP antiguos, más no para los nuevos que sí están sometidos al cumplimiento de una serie de requisitos para su contratación como lo veremos seguidamente. En todo caso lo que correspondió es dictarse una ley que solucione integralmente este problema, como por ejemplo la Ley de la Carrera Administrativa del Servidor Público que se encuentra pendiente de discusión desde hace bastante tiempo en el Congreso de la República.

\section{Procedimiento de contratación (Decreto Legislativo, artículo 4, Reglamento artículo 3)}

El Decreto Legislativo establece como requisito para la celebración del contrato administrativo 
de servicios: (i) requerimiento realizado por la dependencia usuaria; $y$, (ii) existencia de la disponibilidad presupuestaria determinada por la Oficina de Presupuesto de la entidad o quien haga sus veces; el Reglamento desarrolla el procedimiento de contratación, estableciendo tres etapas: (i) preparatoria, que comprende el requerimiento del órgano o entidad orgánica usuaria, que incluye la descripción del servicio a realizar y los requisitos mínimos y las competencias que debe reunir el postulante, así como la descripción de las etapas del procedimiento, la justificación de la necesidad de contratación y la disponibilidad presupuestaria; (ii) convocatoria, que comprende la publicación de la misma en el portal institucional en Internet y en un lugar visible de acceso público del local o de la sede central de la entidad convocante, sin perjuicio de utilizarse, a criterio de la misma, otros medios de información, debiendo hacerse y mantenerse cuando menos cinco días hábiles previos al inicio de la etapa de selección; (iii) selección, que comprende la evaluación objetiva del postulante relacionada con las necesidades del servicio. Debe incluir la evaluación curricular $y$, a criterio de la entidad convocante, la evaluación escrita y entrevista, entre otras que se estimen necesarias según las características del servicio materia de la convocatoria; en todo caso la evaluación se debe realizar tomando en consideración los requisitos relacionados con las necesidades del servicio y garantizando los principios de mérito, capacidad e igualdad de oportunidades, debiendo publicarse el resultado de la evaluación a través de los mismos medios utilizados para publicar la convocatoria, en forma de lista por orden de mérito, que debe contener los nombres de los postulantes y los puntajes obtenidos por cada uno de ellos; y, (iv) suscripción y registro del contrato, que comprende la suscripción del contrato dentro de un plazo no mayor de cinco días hábiles, contados a partir del día siguiente de la publicación de los resultados. Si vencido el plazo, el seleccionado no suscribe el contrato por causas objetivas imputables a él, se debe declarar seleccionada a la persona que ocupa el orden de mérito inmediatamente siguiente, para que proceda la suscripción del contrato dentro del mismo plazo, contado a partir de la respectiva notificación. De no suscribirse el con- trato por las mismas consideraciones anteriores, la entidad convocante puede declarar seleccionada a la persona que ocupa el orden de mérito inmediatamente siguiente o declarar desierto el proceso. Una vez suscrito el contrato la entidad tiene cinco días hábiles para ingresarlo al registro de contratos administrativos de servicios de cada entidad y a la planilla electrónica regulada por el Decreto Supremo No. 018-2007-TR.

Se trata sin duda de un procedimiento transparente, y por ello positivo. La pregunta que nos formulamos es si existe presupuesto para pagar a estos trabajadores ¿por qué no se les incorpora al régimen natural que les corresponde?.

\section{Impedimentos para contratary prohibición de doble percepción (Reglamento, artículo 4)}

No pueden celebrar contratos administrativos de servicios las personas con inhabilitación administrativa o judicial para contratar con el Estado, así como los que tienen impedimento para ser postores o contratistas. Están impedidas de percibir ingresos por este tipo de contrato, aquellas personas que perciban otros ingresos del Estado salvo que, en este último caso, dejen de hacerlo durante el periodo de contratación administrativa de servicios. La prohibición no alcanza cuando la contraprestación que se percibe proviene de la actividad docente o por ser miembros únicamente de un órgano colegiado.

\section{Duración (Decreto Legislativo, artículo 5, Reglamento, artículo 5)}

La norma establece que en este régimen los contratos son a plazo determinado y renovables, sin que responda a una causa objetiva que justifique la contratación a plazo fijo, como sucede en el régimen laboral de la actividad privada, o cuando menos un plazo máximo de contratación cuando se trata de servicios permanentes como ocurre en el régimen del Decreto Legislativo 276 que, como se ha visto, permite excepcionalmente la contratación hasta por tres años. Entonces, teóricamente a este personal se le podría contratar a plazo fijo 
sin límite de tiempo, es decir indefinidamente se podría prorrogar el plazo de los contratos, lo que de por si entraña un contrasentido. ${ }^{5}$

Tal vez, la limitación se pueda dar cuando finalmente se dicte la Ley de la Carrera Administrativa del Servidor Público, que desde hace bastante tiempo se encuentra para ser debatida por el Pleno del Congreso de la República y que, conforme a la Ley Marco del Empleo Público 28175 , de 18 de febrero de 2004 , debió dictarse dentro de los 120 días contados a partir de la publicación de la indicada ley, lo que ocurrió el 19 de febrero del citado año; pues al dictarse la Ley de la Carrera Administrativa, todos los servidores públicos quedarán incorporados a ella.

Lo cierto es que el Reglamento establece con claridad que estos contratos pueden ser prorrogados o renovados "cuantas veces considere la entidad contratante en función de sus necesidades", estableciendo que la duración "no puede se mayor al periodo que corresponde al año fiscal respectivo dentro del cual se efectúa la contratación" y que las prórrogas tampoco pueden exceder del año fiscal.

\section{Contenido del contrato-Derechos y beneficios (Decreto Legislativo, artículo 6, Reglamento, artículos 6, 8, 9 y.10)}

El servidor público contratado bajo este régimen especial goza de los siguientes derechos y beneficios:

a) Jornada máxima de trabajo de $\mathbf{4 8}$ horas a la semana. Un primer comentario consiste en que conforme al Decreto Legislativo 800 se establece para la administración pública una jornada en horario corrido de 7 horas 45 , lo cual podría suponer un tratamiento desigual sin que medie justificación objetiva alguna. Es cierto que la norma establece las 48 horas como máximo, lo que debería llevar a las entidades del Estado a que la jornada de estos servidores públicos sea igual a la de los demás, es decir 7 horas 45 minutos.

El Reglamento señala que las entidades contratantes deben velar por el estricto cumplimiento de la jornada y adoptar las medidas correspondientes con esa finalidad, entre ellas la reducción proporcional de la contraprestación o remuneración por el incumplimiento de las horas no trabajadas excepto en los supuestos que veremos más adelante o la compensación con descanso físico por la prestación de servicios en sobretiempo, lo que significa que, al igual que lo que ocurre en la Administración Pública, no está autorizado el pago de horas extras. Ahora bien, se debe partir de la premisa que el trabajo de horas extras materia de compensación con descanso debe ser prestado voluntariamente por el servidor. Otra de las medidas naturales para el control del cumplimiento de la jornada de trabajo y trabajo en sobretiempo, tendría que ser el registro de asistencia.

b) Descanso de 24 horas continuas por semana; se entiende que se refiere al descanso semanal obligatorio. Dicho descanso debe ser pagado no solo porque así ocurre con los servidores públicos comprendidos en la ley de la Carrera Administrativa o en el régimen laboral de la actividad privada, sino porque el artículo 25 in fine de la Constitución así lo establece. De lo contrario se estaría produciendo un trato discriminatorio. El Reglamento no efectúa ningún desarrollo de este tema.

c) Descanso de 15 días calendario continuo por año cumplido. Aún cuando no lo menciona, se trata en principio del derecho vacacional anual, pues el artículo 25 in fine de la Constitución reconoce el derecho de los trabajadores al descanso semanal y anual remunerados. El tema en discusión es si se justifica o no objetivamente que el descanso 
sea de 15 días cuando el resto de los servidores públicos gozan de 30 días anuales de vacaciones. Conocemos bien que solo cabe un trato discriminatorio ahí donde se dan elementos objetivos que permiten dicho trato, en caso contrario estaríamos frente a una norma que podría ser cuestionable constitucionalmente hablando.

El Reglamento, asimilando a lo que ocurre con la legislación laboral privada en materia de vacaciones establece que el descanso de 15 días debe ser ininterrumpido y pagado después de un año de prestación de servicios, señalándose que la renovación o prórroga no interrumpe el tiempo de servicios acumulado, lo que significa que de concluir el contrato, en la medida que medie prórroga, deberá esperarse a que se cumpla el periodo anual para tener derecho al descanso físico pagado. Nótese que tanto la norma legal como la reglamentaria establecen que el derecho se adquiere "por cada año de servicios cumplido", con lo cual se estaría descartando la posibilidad de pago del denominado "record trunco vacacional" que ocurre normalmente al cese por el tiempo acumulado que no llega al año, y que si es reconocido en el régimen laboral común.

En cuanto a la oportunidad del descanso físico, el Reglamento establece que debe ser determinada por las partes y que, de no producirse acuerdo lo establece la entidad contratante.

Además se prevé que en caso concluya el contrato después del año de servicios sin que el trabajador haya hecho efectiva sus vacaciones, tiene derecho a percibir el pago correspondiente al descanso físico que se le conoce como vacaciones ganadas y no gozadas.

d) Afiliación al régimen contributivo que administra Essalud. Estos servidores públicos son afiliados regulares de este régimen contributivo de acuerdo a lo dispuesto por el artículo 3 de la Ley 26790 -Ley de Modernización de la Seguridad Social en Salud-y sus normas reglamentarias y mo- dificatorias. También están comprendidos sus derechohabientes conforme a la citada ley.

La contribución mensual de $9 \%$ es de cargo de la entidad contratante y se establece sobre una base imponible máxima equivalente al $30 \%$ de la UIT vigente, teniendo en cuenta la base imponible mínima prevista por el artículo 6 de la Ley 26790 vigente, tal como quedó modificada por la Ley 28791 es decir la remuneración mínima vital. Esto significa que la entidad pagará el $9 \%$ entre $S / .550 .00$ que es la actual remuneración mínima vital y $5 / .1,050.00$ que es el equivalente al 30\% de la UIT vigente, y que no aportará por el exceso de la remuneración que perciba el trabajador, lo cual resulta antitécnico pues grava a Essalud quien tendrá que otorgar las prestaciones de salud sin límite, contribuyendo a su desfinanciamiento. De otro lado, tratándose de prestaciones económicas en caso que el trabajador, por razones de enfermedad o de maternidad tenga derecho a un subsidio, este, sólo se calculará hasta el máximo de $\$ / .1,050.00$, perjudicando al servidor que perciba una remuneración mayor, toda vez que su subsidio será diminuto, incumpliéndose así uno de los fines de los seguros sociales según los cuales el trabajador en caso de sufrir una contingencia que le impida trabajar debe percibir un monto similar al que venía ganando cuando se encontraba en actividad a fin de no sufrir menoscabo en su nivel de vida.

Conforme a la Tercera Disposición Complementaria Final, la obligación de pago de esta contribución operará a partir del 1 de enero de 2009.

e) Afiliación a un régimen de pensiones, señalándose que es opcional para quienes ya vienen trabajando bajo contrato de servicios no personales, y obligatoria para las personas que sean contratadas bajo este régimen a partir de su entrada en vigencia, es decir, desde el 29 de junio de 2008. El servidor deberá elegir entre el Sistema Nacional de Pensiones o el Sistema Privado de Pensiones. 


\section{Ius variandi (Reglamento, artículo 7)}

De acuerdo a la norma reglamentaria, las entidades empleadoras por razones objetivas debidamente justificadas, pueden modificar el lugar, tiempo y modo de la prestación de servicios, sin que ello suponga la celebración de un nuevo contrato.

\section{Suspensión del contrato (Reglamento, artículo 12)}

Los supuestos de suspensión perfecta, es decir que no se trabaja y no se percibe la remuneración correspondiente pero continúa vigente el vínculo laboral, opera en caso de permisos personales que sean otorgados en forma excepcional y por causas justificadas al servidor; en tanto que la suspensión imperfecta, que supone que sin trabajar se tiene derecho a percibir la remuneración correspondiente, opera en los supuestos regulados en el régimen contributivo de Essalud, por ejemplo durante los 20 primeros días de incapacidad; así como por ejercicio del derecho de descanso pre y post natal; y cuando la suspensión el contrato sea consecuencia de caso fortuito o fuerza mayor debidamente comprobados.

\section{Extinción del contrato (Reglamento, artículo 13)}

El contrato se extingue por: (i) fallecimiento del contratado; (ii) extinción de la entidad contratante; (iii) decisión unilateral del contratado, que equivale a la renuncia en un contrato a plazo indeterminado, que en el fondo es lo que ocurre en este "régimen", pues como ya se ha visto los contratos pueden ser prorrogados indefinidamente. En este supuesto el contratado debe comunicar por escrito su decisión a la entidad contratante con una anticipación de 30 días naturales previos al cese. Este plazo puede ser exonerado por la autoridad competente designada por cada entidad o en su defecto por la Dirección General de Administración o la que haga sus veces en cada entidad, por propia iniciativa o a pedido del contratado. En este último caso, el pedido de exoneración se entenderá aceptado si no es rechazado por escrito dentro del tercer día natural de presentado; (iv) mutuo acuerdo entre el contratado y la entidad contratante; (v) invalidez absoluta permanente sobreviniente del contratado; (vi) decisión unilateral de la entidad contratante, sustentada en el incumplimiento injustificado de las obligaciones derivadas del contrato, o en la deficiencia en el cumplimiento de las tareas encomendadas, en cuyo caso la entidad debe imputar al contratado el incumplimiento mediante notificación, quien tiene un plazo de cinco días hábiles para hacer uso de su derecho de defensa. Vencido este plazo la entidad debe decidir, en forma motivada y según los criterios de razonabilidad y proporcionalidad, si resuelve o no el contrato, comunicándolo al contratado. Esta decisión agota la vía administrativa. Cuando el contrato sea resuelto unilateralmente por la entidad pública, es decir sin mediar incumplimiento del contratado, el juez podrá aplicar una penalidad o indemnización equivalente a las contraprestaciones (remuneraciones) dejadas de percibir hasta un importe máximo equivalente a dos meses; (vii) inhabilitación administrativa, judicial o política por más de tres meses; $y$, (viii) vencimiento del plazo del contrato.

\section{Solución de controversias (Reglamento, artículo 16)}

Los conflictos derivados de la prestación de los servicios contratados será resuelto por el órgano responsable de la entidad, quedando agotada la vía administrativa en dicha instancia única, procediendo en todo caso la acción contencioso administrativa conforme a las reglas de dicho proceso.

\section{Responsabilidad administrativa y civil (Decreto Legislativo, artículo 7)}

Los funcionarios o servidores públicos que contraten personas para prestar servicios no autónomos, es decir subordinados fuera de las reglas del presente régimen, es decir simulando contratos de locación de servicios, incurren en falta administrativa y en consecuencia son responsables civiles por los daños y perjuicios que le origina el Estado. 
En realidad, lo que sucede es que, los titulares de los pliegos que autorizaron contra la ley la contratación "por servicios no personales" (cuando estos más personales no podían ser y además subordinados) siempre han sido responsables civilmente por los daños ocasionados al Estado quien, por disposición de las sentencias consentidas o ejecutoriadas se ha visto obligado a pagar los derechos y beneficios sociales que correspondían a estos trabajadores que jamás debieron ser contratados de esa forma. Lo que sucede es que, se conozca, nunca se ha iniciado un juicio de responsabilidad, por lo que tal conducta al quedar impune prosperó.

\section{COMENTARIOS FINALES}

El mérito de esta norma reside en haber puesto punto final a un sistema de contratación fraudulento que indebidamente venía utilizando el Estado, reconociéndose a los servidores sujetos a dicha contratación, derechos mínimos. El problema es que estos trabajadores si recurren al Poder Judicial o al Tribunal Constitucional es muy probable que se les reconozca el íntegro de los derechos y beneficios sociales que le puedan corresponder bien sea de acuerdo al régimen de la Carrera Administrativa si prestan servicios en una entidad pública donde se aplica dicho régimen, o el del régimen laboral de la actividad privada si laboran en una entidad cuyos servidores se regulan por el régimen laboral de la actividad privada.

Tal vez otra debió ser la solución que hubiera consistido en incorporar a estos servidores de acuerdo al régimen que les corresponda sin que ello implicara mayor gasto al Estado en la medida que el monto percibido sirviera, no solo para solventar la remuneración del trabajador y sus beneficios colaterales, sino también las contribuciones a Essalud y Pensiones. La objeción que podría plantearse a esta solución es que ello podría suponer una rebaja de remuneraciones que se encuentra recusada por la ley y que podría constituir un acto de hostilidad equivalente al despido. Esto es cierto parcialmente, porque para que configure el acto de hostilidad, la rebaja debe ser "inmotivada" y en la propuesta la rebaja no solamente es aparente, sino que, de existir, sería absolutamente "motivada" toda vez que el monto que percibian como remuneración simplemente serviría para, desagregado, cumplirse con todas y cada una de las obligaciones laborales y de seguridad social, por lo cual, en el fondo no habria tal disminución y de insistirse en su existencia que tal vez podría darse en lo que respecta a la contribución a Essalud que es a cargo del empleador, esta sería totalmente motivada en la medida que lo que se estaría consiguiendo es formalizar una relación contractual que venía siendo ejecutada al margen de la ley y con privación de derechos de los trabajadores. Además se trataría, sin duda, de una solución más beneficiosa para aquellos.

Resulta entonces aconsejable acelerar el debate y la promulgación de la Ley de la Carrera Administrativa del Servidor Público y de las otras normas previstas por la Ley Marco del Empleo Público, a fin de que de una vez los servidores públicos cuenten con un régimen propio y general y de este modo se salvaguarden debidamente los derechos y beneficios sociales a los que con justicia deben acceder por los servicios que prestan a la Nación. 